\title{
Propacetamol as an alternative of ketorolac for postoperative pain management using patient-controlled analgesia
}

Received April 26, 2017

Revised 1st, July 12, 2017

2nd, July 31, 2017

Accepted July 31, 2017

\section{Corresponding author}

Jihyun An, M.D.

Department of Anesthesiology and Pain Medicine, Daegu Fatima Hospital, 99, Ayang-ro, Dong-gu,

Daegu 41199, Korea

Tel: 82-53-940-7434

Fax: 82-53-954-7417

E-mail: anji43@naver.com

\section{Sang Gyun Kim, Jihyun An, Ji-Hyang Lee, Eunju Kim, Sang-Gon Lee, and Kwangsuk Sim}

Department of Anesthesiology and Pain Medicine, Daegu Fatima Hospital, Daegu, Korea
Background: The objective of this study was to examine effect of propacetamol in comparison with ketorolac in intravenous patient-controlled analgesia after gynecologic surgeries.

Methods: Patients aged 18 to 70 years and undergoing laparoscopic gynecologic surgeries were selected. They were randomly allocated to either group K (180 mg of ketorolac with fentanyl and ramosetron) or group P (10 g of propacetamol with fentanyl and ramosetron). Their vital signs and visual analogue scale (VAS) were examined six times ( 0 min, $15 \mathrm{~min}, 30 \mathrm{~min}, 60 \mathrm{~min}, 12 \mathrm{~h}$, and $24 \mathrm{~h}$ ) and laboratory workup was done 48 hours after PCA application. Development of side effects was examined 15 minutes after the PCA application. Data from 111 patients were used for the final analysis.

Results: There were no significant differences in changes of systolic and diastolic blood pressures, heart rate, body temperature, and VAS between the groups ( $P=0.325,0.835$, $0.346,0.524$, and 0.382 , respectively). There were significant differences in the levels of hemoglobin, hematocrit, blood urea nitrogen, and international normalized ratio but it was not clinically meaningful. The development of vomiting, dizziness, and headache were not significantly different between the groups and no patient developed pruritus. Although the overall number of patients with nausea was higher in group $P$ with statistical significance $(P=0.002)$, there were no significant differences between the groups when examined at each detection time.

Conclusions: The present study suggested propacetamol as a possible alternative of ketorolac in postoperative care after laparoscopic gynecologic surgeries.

Key Words: Analgesia, Ketorolac, Patient-controlled, Propacetamol.

\section{INTRODUCTION}

Postoperative pain is not avoidable but can be controlled. Appropriate and rapid management of postoperative pain not only influences the patient's condition but also reduces medical costs. Intravenous patient controlled analgesia (PCA) compensates limitations of traditional pro re nata analgesics, including intra-patient variability in analgesic needs, admin- istrative delays, and variability in serum drug levels. PCA delivers analgesic opioids in an optimal manner and minimizes the effects of pharmacokinetic and pharmacodynamic variability in each patient, providing improved patient satisfaction and superior postoperative pain control [1].

Opioids are used to control postoperative pain by interacting with opioid receptors in the central nervous system to interrupt delivery of pain impulses [2]. The effect of opioids

This is an Open Access article distributed under the terms of the Creative Commons Attribution Non-Commercial License (http://creativecommons.org/licenses/by-nc/4.0) which permits unrestricted non-commercial use, distribution, and reproduction in any medium, provided the original work is properly cited. 
is tremendous in management of postoperative pain and not only patients but also anesthesiologists prefer its use; however, the use of parenteral opioids often induces side effects such as postoperative nausea and vomiting (PONV), undesirable sedation, dependency, constipation, and paralytic ileus. Application of limited amount of opioid in patient-controlled analgesia (PCA) is necessary to prevent the development of opioid-related side effects; therefore, additive pain controllers such as ketorolac are often used [3-6].

Ketorolac, a nonsteroidal anti-inflammatory drug (NSAID) often used with opioids, controls pain by inhibiting synthesis of prostaglandins [3]. It is reported that ketorolac reduces opioid dose by $36 \%$ and development of PONV or sedation is observed less with use of ketorolac [6]. However, use of ketorolac showed higher risk of postoperative bleeding and anastomotic leakage after colorectal surgery due to gastrointestinal and antiplatelet effects $[7,8]$, slowed wound healing, and reduced kidney function $[9,10]$. Therefore, use of opioid with ketorolac in PCA to vulnerable patients, especially ones with kidney problems or unstable hemodynamic states, is limited. In addition, a prolonged onset of the analgesic action (30-60 $\mathrm{min}$ ) is another weakness of ketorolac in control of acute pain [11].

In contrast, propacetamol, a prodrug of acetaminophen, is also known to reduce opioid dose by $37 \%$ [12] and presents a safer pharmacological profile. A gram of propacetamol infused intravenously hydrolyzes into $0.5 \mathrm{~g}$ of acetaminophen and pharmacologically inactive N,N-diethylglycine within 7 min [13-15]. Acetaminophen is widely used to control mild to moderate pain in clinical conditions and is well known for its inhibitory effect on central cyclooxygenase. Analgesic effects of acetaminophen can be explained by its interaction with multiple other neurotransmitters which involve serotonergic, opioidergic, noradrenergic, cholinergic, and nitric acid-synthase systems. Its interaction with the serotonergic system, in particular, is known to be associated with production of the analgesic effects [16].

It has been reported that the combined administration of opioids and NSAID increases efficacy and prevents postoperative central sensitization $[17,18]$. This combination also reduces opioids dose [19]. With this regard, the objective of this study was to examine effect of propacetamol in comparison with ketorolac in intravenous patient controlled analgesia (IV PCA) after gynecologic surgeries.

\section{MATERIALS AND METHODS}

The present study was approved by the hospital's Institutional Review Board. All participants gave written, informed consent before the study procedures.

\section{Study subjects}

Power and Sample Calculators (Available from http://powerandsamplesize.com/Calculators/) was used for sample size calculation. The suggested minimum sample size was 53 per group at the level of power $=0.8, \alpha=0.05$, and effect size of 1.2, which was estimated from a previous study [20]. Considering dropouts and failures, 60 subjects ( $14 \%$ was added) were recruited for each group. A total of 120 patients aged 18 to 70 years and scheduled to undergo laparoscopic gynecologic surgeries between January and June 2016 and whose American Society of Anesthesiologists physical status were either I or II were enrolled in the present study. The types of laparoscopic gynecologic operations included myomectomy, total hysterectomy, ovary cystectomy, and salpingooophorectomy. The patients were excluded if they had any kind of severe hepatic, renal, or gastric diseases; if they were given additional analgesics, anti-inflammatory drugs, or antipyretic drugs during the study; or if ketorolac, propacetamol, or fentanyl were contraindicated. The total number of study subjects was 111 and they were randomly allocated to two different intervention groups using a computer-generated randomized table.

\section{Preparations and measurements}

Within a month before their scheduled surgeries, preoperative laboratory workup was done. When patients arrived at the hospital for administration, each subject's body weight and height were measured. All patients were administered 0.2 mg of glycopyrrolate and 2 mg of midazolam intramuscularly, and $20 \mathrm{mg}$ of famotidine intravenously as premedication. During the operation, the vital signs were monitored using an electrocardiogram, blood pressure cuff, pulse oximeter, and a bispectral index monitor (Model A 3000, Aspect Medical Systems, Inc., USA).

Moreover, $2 \mathrm{mg} / \mathrm{kg}$ of propofol, $0.6-0.8 \mathrm{mg} / \mathrm{kg}$ of rocuronium, and remifentanil were used for induction. During the 
operation, $3.5 \mu \mathrm{g} / \mathrm{ml}$ propofol in Schnider mode and remifentanil were used in target controlled infusion with total intravenous anesthesia (Orchestra ${ }^{\circledR}$ Base Primea, Fresenius Kabi, France).

The subjects allocated to group K were given $180 \mathrm{mg}$ of ketorolac, $0.3 \mathrm{mg}$ of ramosetron, and 1,000 $\mu$ g of fentanyl $(\mathrm{n}=$ 57) while patients in group $P$ were administered $10 \mathrm{~g}$ of propacetamol, $0.3 \mathrm{mg}$ of ramosetron, and 1,000 $\mu \mathrm{g}$ of fentanyl (n =54). All patients were administered $0.3 \mathrm{mg}$ of ramosetron in order to prevent PONV and all agents were mixed in saline so that the total volume of PCA added up to $100 \mathrm{ml}$ (Automed AM3400, ACE medical, Korea). The PCA was loaded $1 \mathrm{ml} /$ $\mathrm{h}$ with $3 \mathrm{ml}$ of bolus and with 15 minutes lock-out intervals. For rescue analgesia, 50 to $100 \mu \mathrm{g}$ of fentanyl was infused intravenously. Vital signs (systolic and diastolic blood pressure, heart rate, and body temperature [tympanic membrane ${ }^{\mathrm{TM}}$, bilateral) and visual analogue scale (VAS) were checked right after PCA application. After durations of 15, 30, 60 minutes, and 12 and 24 hours after PCA application, vital signs, VAS, as well as any development of side effects (nausea, vomiting, dizziness, headache, or pruritus) were examined. The total PCA infusion time and amount of PCA infused for 24 hours were recorded. For the study subjects who complained of severe nausea, 5-10 mg of metoclopramide was administered intravenously as needed. Forty-eight hours after the surgeries, postoperative laboratory workup was done. The levels of hemoglobin ( $\mathrm{Hb})$, hematocrit (Hct), platelet (plt), prothrombin time (PT), activated partial thromboplastin time (aPTT), aspartate aminotransferase (AST), alanine aminotransaminase (ALT), blood urea nitrogen (BUN), creatinine (Cr), and international normalized ratio (INR) were tested in the workup.

\section{Data analysis}

To compare the groups, Student's $t$ tests were performed for variables that were normally distributed and MannWhitney $U$ tests were performed to compare variables that

Table 1. General Characteristics of Study Subjects

\begin{tabular}{lccc}
\hline \multicolumn{1}{c}{ Variables } & Group K $(\mathrm{n}=57)$ & Group P $(\mathrm{n}=54)$ & $\mathrm{P}$ value \\
\hline Age $(\mathrm{yr})$ & $44.3 \pm 9.2$ & $45.1 \pm 10.5$ & 0.673 \\
Weight $(\mathrm{kg})$ & $59.9 \pm 9.7$ & $59.5 \pm 9.3$ & 0.847 \\
Height $(\mathrm{cm})$ & $158.3 \pm 5.1$ & $159.9 \pm 5.6$ & 0.131 \\
Operation time $(\mathrm{min})$ & $64.0(52.0-80.0)$ & $65.5(53.0-88.0)$ & 0.743 \\
Total PCA infusion time $(\mathrm{h})$ & $66.8(51.0-69.1)$ & $58.5(47.3-66.6)$ & 0.208 \\
Amount of PCA infused for 24 $\mathrm{h}(\mathrm{ml})$ & $45.1(35.1-58.0)$ & $43.2(38.2-54.3)$ & 0.790 \\
Amount of bolus PCA infused for 24 $\mathrm{h}(\mathrm{ml})$ & $18.0(9.0-30.0)$ & $18.0(9.0-27.0)$ & 0.722 \\
\hline
\end{tabular}

Values are presented as mean \pm SD or median (interquartile range). PCA: patient controlled analgesia, Group K: $180 \mathrm{mg}$ of ketorolac mixed with fentanyl and ramosetron in IV PCA, Group P: $10 \mathrm{~g}$ of propacetamol mixed with fentanyl and ramosetron in IV PCA. There was no significant difference between the groups.

Table 2. Characteristics of PCA Infusion according to Type of Operation

\begin{tabular}{|c|c|c|c|c|}
\hline Operation & Variables & Group K & Group P & $P$ value \\
\hline \multirow[t]{3}{*}{ LM } & Total PCA infusion time (h) & $65.0(45.3-68.7)$ & $61.1(47.7-71.7)$ & 0.648 \\
\hline & Amount of PCA infused for $24 \mathrm{~h}(\mathrm{ml})$ & $47.0(39.7-58.0)$ & $43.2(38.2-54.0)$ & 0.582 \\
\hline & Amount of bolus PCA infused for $24 \mathrm{~h} \mathrm{(ml)}$ & $15.0(12.0-30.0)$ & $18.0(9.0-27.0)$ & 0.966 \\
\hline \multirow[t]{3}{*}{ TLH } & Total PCA infusion time $(\mathrm{h})$ & $67.4(16.0-69.6)$ & $56.0(45.8-65.7)$ & 0.301 \\
\hline & Amount of PCA infused for $24 \mathrm{~h} \mathrm{(ml)}$ & $47.8(35.1-61.0)$ & $48.3(40.0-57.4)$ & 0.402 \\
\hline & Amount of bolus PCA infused for $24 \mathrm{~h}(\mathrm{ml})$ & $20.3(9.0-30.2)$ & $18.0(12.0-33.0)$ & 0.629 \\
\hline \multirow[t]{3}{*}{ OC/SO } & Total PCA infusion time $(\mathrm{h})$ & $67.0(60.0-69.1)$ & $63.2(56.5-65.8)$ & 0.160 \\
\hline & Amount of PCA infused for $24 \mathrm{~h}$ (ml) & $44.0(33.6-57.0)$ & $40.8(37.3-44.0)$ & 0.957 \\
\hline & Amount of bolus PCA infused for $24 \mathrm{~h}(\mathrm{ml})$ & $15.1(6.0-27.0)$ & $15.0(9.0-18.1)$ & 0.845 \\
\hline
\end{tabular}

Values are presented as median (interquartile range). Mann-Whitney $U$ tests were performed. PCA: patient controlled analgesia, LM: laparoscopic myomectomy, TLH: total laparoscopic hysterectomy, OC/SO: ovary cystectomy or salpingo-oophorectomy. 
were not normally distributed. Fisher's exact chi-square tests were used to examine the development of side effects for 24 hours after PCA application in both groups. Repeated measure analysis of variance was used to examine changes in systolic and diastolic blood pressure, heart rate, body temperature, and VAS for 24 hours after PCA application. In addition, paired $t$ tests were performed repetitively to compare changes in vital signs and VAS over time within a group.
Analysis of covariance (ANCOVA) was performed to compare postoperative laboratory workup results with pre-assessment results as covariates.

All statistical analyses were performed with SAS software version 9.4 (SAS Institute Inc., USA), and P value $<0.05$ was considered to indicate statistical significance.
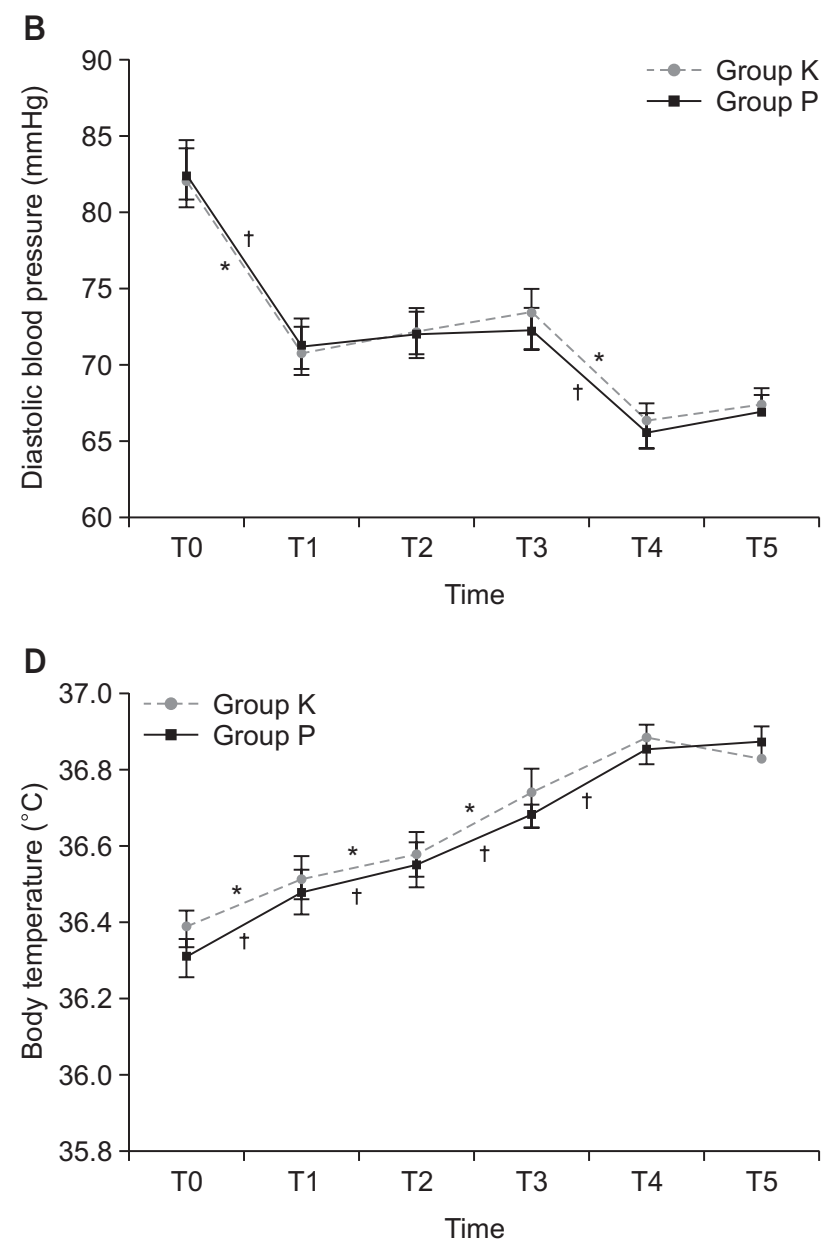

Fig. 1. Values are presented as the mean \pm SE. Repeated measures ANOVA were performed. In addition, paired t-tests were performed repetitively for each time segment to compare changes in SBP, DBP, HR, and BT within a group. Group K: $180 \mathrm{mg}$ of ketorolac mixed with fentanyl and ramosetron in the IV PCA, Group P: 10 g of propacetamol mixed with fentanyl and ramosetron in IV PCA. TO, T1, T2, T3, T4, T5: 0 min, 15 min, 30 min, 60 min, 12 h, and 24 h after PCA application. There was significant effect of time (P values are all $<0.001)$, but no significant difference between the groups $(P=0.325,0.835,0.346$, and 0.524 , respectively). *Indicates significant differences for the time intervals within the group K ( $\mathrm{P}$ values for SBP changes: TO-T1 $<0.001, \mathrm{~T} 1-\mathrm{T} 2<0.001, \mathrm{~T} 2-\mathrm{T} 3=0.189$, T3-T4 < 0.001, T4-T5 = 0.200. P values for DBP changes: T0-T1<0.001, T1-T2 = 0.301, T2-T3 = 0.211, T3-T4<0.001, T4-T5 $=0.472$. $\mathrm{P}$ values for HR changes: T0-T1 < 0.001, T1-T2 = 0.008, T2-T3 = 0.045, T3-T4<0.001, T4-T5 = 0.952. P values for BT changes: T0-T1 $=0.022, \mathrm{~T} 1-\mathrm{T} 2=0.031, \mathrm{~T} 2-\mathrm{T} 3<0.001, \mathrm{~T} 3-\mathrm{T} 4=0.061, \mathrm{~T} 4-\mathrm{T} 5=0.244) .{ }^{\dagger}$ Indicates significant differences for the time intervals within the group P ( $\mathrm{P}$ values for SBP changes: T0-T1 $=0.039$, T1-T2 = 0.006, T2-T3 = 0.043, T3-T4 < 0.001, T4$\mathrm{T} 5=0.457$. $\mathrm{P}$ values for DBP changes: T0-T1 < 0.001, T1-T2 $=0.468, \mathrm{~T} 2-\mathrm{T} 3=0.863, \mathrm{~T} 3-\mathrm{T} 4<0.001, \mathrm{~T} 4-\mathrm{T} 5=0.333$. $\mathrm{P}$ values for HR changes: T0-T1<0.001, T1-T2 = 0.152, T2-T3 = 0.005, T3-T4=0.013, T4-T5=0.615. $\mathrm{P}$ values for BT changes: T0-T1 = $0.001, \mathrm{~T} 1-\mathrm{T} 2=0.013, \mathrm{~T} 2-\mathrm{T} 3<0.001, \mathrm{~T} 3-\mathrm{T} 4=0.015, \mathrm{~T} 4-\mathrm{T} 5=0.756)$. 


\section{RESULTS}

Table 1 displays the general characteristics of study subjects. There were no statistical differences between the groups regarding age, weight, and height $(\mathrm{P}=0.673,0.847$, and 0.131 , respectively). For both the groups, the operation took about one hour. The median values for PCA infusion time and amount of PCA infused for 24 hours was lower for group $\mathrm{P}$ than for group $\mathrm{K}$; however, there were no significant differences $(\mathrm{P}=0.208$ and 0.790$)$.

The number of patients who underwent laparoscopic myomectomy (LM) was 31. A total of 46 patients received total laparoscopic hysterectomy (TLH). Ovary cystectomy or salpingo-oophorectomy (OC/SO) was performed for 34 patients. For group K, 17, 23, and 17 patients received LM, TLH, and OC/SO, respectively. For group P, 14, 23, and 17 patients underwent LM, TLH, and OC/SO, respectively. There were no significant differences in the total PCA infusion time, amount of PCA infused for 24 hours, and amount of bolus PCA infused for 24 hours between the groups (Table 2).

Fig. 1 illustrates the changes in systolic and diastolic blood pressures, heart rate, and body temperature for 24 hours after PCA application. The change patterns for group $\mathrm{P}$ are quite similar to that for group K; there were no significant differences between the groups $(\mathrm{P}=0.325,0.835,0.346$, and 0.524 , respectively).

The changes in VAS after PCA application are illustrated in
Fig. 2. For both groups, there were gradual decreases in VAS with time. The changes in VAS after PCA application were not significantly different between the groups $(\mathrm{P}=0.382)$.

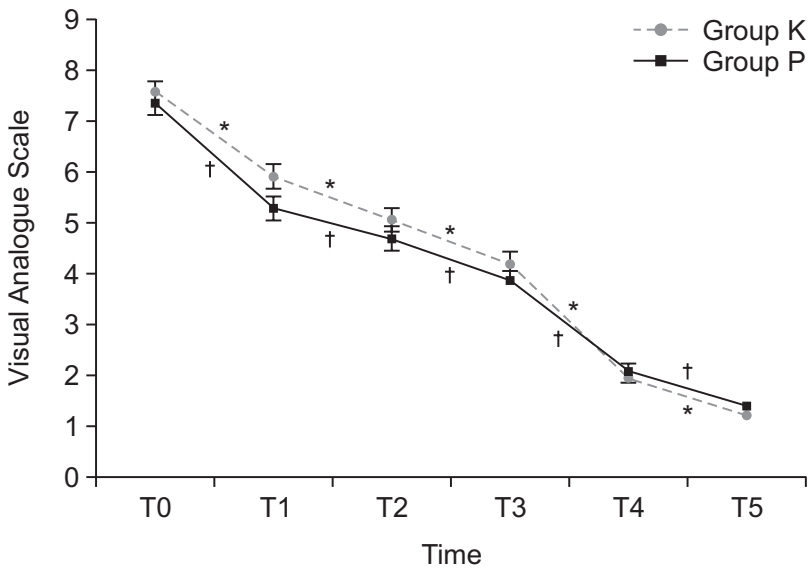

Fig. 2. Values are presented as the mean \pm SE. Repeated measures ANOVA was performed. Group K: 180 mg of ketorolac mixed with fentanyl and ramosetron in IV PCA, Group P: 10 $\mathrm{g}$ of propacetamol mixed with fentanyl and ramosetron in IV PCA. T0, T1, T2, T3, T4, T5: 0 min, 15 min, 30 min, 60 min, 12 $\mathrm{h}$, and $48 \mathrm{~h}$ after PCA application. There was significant effect of time $(P<0.001)$ but no significant difference between the groups ( $P=0.382)$. *Indicates significant differences for the time intervals within the group $K(P$ values for VAS changes: T0-T1 $<0.001, \mathrm{~T} 1-\mathrm{T} 2<0.001, \mathrm{~T} 2-\mathrm{T} 3<0.001$, T3-T4 $<0.001$, T4-T5 $<0.001) .{ }^{\dagger}$ Indicates significant differences for the time intervals within the group $\mathrm{P}$ ( $\mathrm{P}$ values for VAS changes: TO-T1 < $0.001, \mathrm{~T} 1-\mathrm{T} 2=0.002, \mathrm{~T} 2-\mathrm{T} 3<0.001, \mathrm{~T} 3-\mathrm{T} 4<0.001, \mathrm{~T} 4-\mathrm{T} 5$ $<0.001)$.

Table 3. Comparison of Laboratory Workup Results

\begin{tabular}{|c|c|c|c|c|c|}
\hline \multirow{2}{*}{ Variable } & \multicolumn{2}{|c|}{ Group K (n = 57) } & \multicolumn{2}{|c|}{ Group P $(n=52)$} & \multirow{2}{*}{ P value } \\
\hline & Baseline & $48 \mathrm{~h}$ & Baseline & $48 \mathrm{~h}$ & \\
\hline $\mathrm{Hb}$ & $11.79 \pm 1.52$ & $10.56 \pm 1.40$ & $12.29 \pm 1.50$ & $11.30 \pm 1.27$ & 0.023 \\
\hline Hct & $35.43 \pm 3.84$ & $31.78 \pm 3.68$ & $36.53 \pm 3.46$ & $33.60 \pm 3.19$ & 0.027 \\
\hline plt & $275.61 \pm 73.76$ & $213.86 \pm 53.43$ & $270.35 \pm 57.72$ & $230.83 \pm 54.54$ & 0.758 \\
\hline BUN & $12.01 \pm 3.69$ & $6.26 \pm 2.69$ & $12.18 \pm 4.00$ & $5.00 \pm 2.65$ & 0.005 \\
\hline $\mathrm{Cr}$ & $0.67 \pm 0.10$ & $0.61 \pm 0.10$ & $0.68 \pm 0.10$ & $0.62 \pm 0.11$ & 0.955 \\
\hline AST & $19.42 \pm 9.42$ & $17.33 \pm 5.96$ & $19.42 \pm 5.51$ & $19.17 \pm 9.14$ & 0.197 \\
\hline ALT & $16.47 \pm 14.21$ & $12.40 \pm 6.35$ & $16.13 \pm 9.75$ & $14.17 \pm 9.21$ & 0.135 \\
\hline PT & $11.77 \pm 0.71$ & $12.72 \pm 2.69$ & $11.57 \pm 0.61$ & $11.93 \pm 0.64$ & 0.079 \\
\hline aPTा & $29.20 \pm 3.52$ & $30.94 \pm 3.78$ & $34.30 \pm 39.41$ & $30.38 \pm 4.20$ & 0.400 \\
\hline INR & $1.03 \pm 0.06$ & $1.09 \pm 0.09$ & $1.02 \pm 0.05$ & $1.05 \pm 0.05$ & 0.017 \\
\hline
\end{tabular}

Values are presented as mean $\pm \mathrm{SD}$. Analysis of covariance was performed with pre-assessment as a covariate. Postoperative levels of $\mathrm{Hb}$, Hct, BUN, and INR were significantly different between the groups ( $P=0.026,0.027,0.005,0.017)$. Hb: hemoglobin, Hct: hematocrit, plt: platelet, BUN: blood urea nitrogen, Cr: creatinine, AST: aminotransferase, ALT: aminotransaminase, PT: prothrombin time, aPTT: activated partial thromboplastin, INR: international normalized ratio. 
Except for two patients who were discharged before 48 hours past PCA application, postoperative laboratory workup was established for every study subject. The mean values of Hb, Hct, plt, BUN, Cr, AST, ALT, PT, aPTT, and INR and results of ANCOVA with pre-assessment as a covariate are presented in Table 3. The mean levels of $\mathrm{Hb}$, Hct, plt were decreased in both groups. There were dramatic decreases in the mean value of BUN while the level of $\mathrm{Cr}$ remained quite stable. The differences in mean AST levels were 2.09 in group
$\mathrm{K}$ and 0.25 in group $\mathrm{P}$ and that of ALT levels were 4.07 and 1.96, respectively. Mean PT was elongated in both groups. The mean levels of aPTT were increased in group $\mathrm{K}$ but were decreased in group P. Postoperative levels of $\mathrm{Hb}, \mathrm{Hct}, \mathrm{BUN}$, and INR were significantly different between the groups $(\mathrm{P}=$ 0.026, 0.027, 0.005, 0.017).

Development of side effects including nausea, vomiting, dizziness, headache, and pruritus was examined five times for 24 hours after PCA application (15 min, $30 \mathrm{~min}, 60 \mathrm{~min}$,

\begin{tabular}{|c|c|c|c|c|c|c|c|c|c|c|c|}
\hline \multirow{2}{*}{ Detection time } & \multirow{3}{*}{$\begin{array}{l}\text { Group } \\
\text { Group K }\end{array}$} & \multicolumn{6}{|c|}{ Nausea } & \multicolumn{4}{|c|}{ Vomiting } \\
\hline & & \multicolumn{4}{|c|}{ Patients with S/E } & \multirow{3}{*}{$\begin{array}{l}\mathbf{N}(\%) \\
0(0.0) \\
1(1.9)\end{array}$} & \multirow{3}{*}{$\begin{array}{c}\mathbf{P} \text { value } \\
0.487\end{array}$} & \multicolumn{2}{|c|}{ Patients with S/E } & \multirow{3}{*}{$\begin{array}{l}\mathbf{N}(\%) \\
0(0.0) \\
0(0.0)\end{array}$} & \multirow{3}{*}{$\begin{array}{c}\text { P value } \\
-\end{array}$} \\
\hline $\mathrm{T} 1$ & & & & & & & & & & & \\
\hline & Group P & 1 & & & & & & & & & \\
\hline \multirow[t]{2}{*}{$\mathrm{T} 2$} & Group K & & & & & $0(0.0)$ & \multirow{2}{*}{0.234} & & & $0(0.0)$ & \multirow{2}{*}{-} \\
\hline & Group P & 1 & 2 & & & $2(3.7)$ & & & & $0(0.0)$ & \\
\hline \multirow[t]{2}{*}{ T3 } & Group K & & & & & $0(0.0)$ & \multirow{2}{*}{0.118} & & & $0(0.0)$ & \multirow{2}{*}{0.234} \\
\hline & Group P & 2 & 3 & 4 & & $3(5.6)$ & & 2 & 3 & $2(3.7)$ & \\
\hline \multirow[t]{2}{*}{$\mathrm{T} 4$} & Group K & & & & & $0(0.0)$ & \multirow{2}{*}{0.053} & & & $0(0.0)$ & \multirow{2}{*}{0.487} \\
\hline & Group P & 2 & 4 & 5 & 6 & $4(7.4)$ & & 2 & & $1(1.9)$ & \\
\hline \multirow[t]{2}{*}{ T5 } & Group K & & & & & $0(0.0)$ & \multirow{2}{*}{0.053} & & & $0(0.0)$ & \multirow{2}{*}{ - } \\
\hline & Group P & 3 & 6 & 7 & 8 & $4(7.4)$ & & & & $0(0.0)$ & \\
\hline \multirow{2}{*}{$\begin{array}{l}\text { Total number of } \\
\text { patients with } S / E\end{array}$} & Group K & & & & & $0(0.0)$ & \multirow{2}{*}{0.002} & & & $0(0.0)$ & \multirow{2}{*}{0.234} \\
\hline & Group P & & & & & $8(14.8)$ & & & & $2(3.7)$ & \\
\hline
\end{tabular}

\begin{tabular}{|c|c|c|c|c|c|c|c|c|c|c|c|}
\hline \multirow{2}{*}{ Detection time } & \multirow{2}{*}{ Group } & \multicolumn{5}{|c|}{ Dizziness } & \multicolumn{5}{|c|}{ Headache } \\
\hline & & \multicolumn{3}{|c|}{ Patients with S/E } & \multirow{2}{*}{$\begin{array}{l}\mathbf{N}(\%) \\
1(1.8)\end{array}$} & \multirow{3}{*}{$\begin{array}{c}\text { P value } \\
1.000\end{array}$} & \multicolumn{3}{|c|}{ Patients with S/E } & \multirow{2}{*}{$\frac{\mathbf{N}(\%)}{0(0.0)}$} & \multirow{2}{*}{$P$ value } \\
\hline \multirow[t]{2}{*}{$\mathrm{T} 1$} & Group K & $1^{\prime}$ & & & & & & & & & \\
\hline & Group P & 1 & & & $1(1.9)$ & & & & & $0(0.0)$ & \\
\hline \multirow[t]{2}{*}{$\mathrm{T} 2$} & Group K & $1^{\prime}$ & & & $1(1.8)$ & \multirow{2}{*}{1.000} & & & & $0(0.0)$ & \multirow{2}{*}{ - } \\
\hline & Group P & 1 & & & $1(1.9)$ & & & & & $0(0.0)$ & \\
\hline \multirow[t]{2}{*}{ T3 } & Group K & & & & $0(0.0)$ & \multirow{2}{*}{0.487} & & & & $0(0.0)$ & \multirow{2}{*}{ - } \\
\hline & Group P & 1 & & & $1(1.9)$ & & & & & $0(0.0)$ & \\
\hline \multirow[t]{2}{*}{$\mathrm{T} 4$} & Group K & 2 & & & $1(1.8)$ & \multirow{2}{*}{0.612} & & & & $0(0.0)$ & \multirow{2}{*}{0.487} \\
\hline & Group P & 5 & 6 & & $2(3.7)$ & & 6 & & & $1(1.9)$ & \\
\hline \multirow[t]{2}{*}{ T5 } & Group K & $2^{\prime}$ & $3^{\prime}$ & & $2(3.5)$ & \multirow{2}{*}{0.673} & & & & $0(0.0)$ & \multirow{2}{*}{0.112} \\
\hline & Group P & 5 & 6 & 9 & $3(5.6)$ & & 6 & 7 & 10 & $3(5.6)$ & \\
\hline \multirow{2}{*}{$\begin{array}{l}\text { Total number of } \\
\text { patients with } S / E\end{array}$} & Group K & & & & $3(5.3)$ & \multirow{2}{*}{0.712} & & & & $0(0.0)$ & \multirow{2}{*}{0.112} \\
\hline & Group P & & & & $4(7.4)$ & & & & & $3(5.6)$ & \\
\hline
\end{tabular}

Fig. 3. Values are presented as number (\%). Each colored-square represents a study subject and a square with the same color and number represents an identical individual. Fisher's exact chi-square tests were performed. Group K: 180 mg of ketorolac mixed with fentanyl and ramosetron in IV PCA, Group P: 10 g of propacetamol mixed with fentanyl and ramosetron in IV PCA. T1, T2, T3, T4, T5: $15 \mathrm{~min}, 30 \mathrm{~min}, 60 \mathrm{~min}, 12 \mathrm{~h}$, and $24 \mathrm{~h}$ after surgery. S/E: side effect. A total of 13 patients experienced side effects, three from group $\mathrm{K}$ and 10 from group $\mathrm{P}$ (five patients experienced more than one type of side effects). There were no significant differences in the development of nausea, vomiting, dizziness, and headache between the groups at each time segments. However, the overall development of nausea for 24 hours was significantly different between the groups $(P=0.002)$. 
$12 \mathrm{~h}$, and $24 \mathrm{~h}$ ). Fig. 3 illustrates detailed development of side effects at each time segment and compares overall development of side effects between the groups. The total number of patients who experienced any type of side effects was 13, three from the group $\mathrm{K}$ and ten from the group $\mathrm{P}$, within 24 hours after surgery. All three patients in group K experienced dizziness. Most of the patients in group $\mathrm{P}$ experienced nausea and five patients experienced more than one type of side effect. No patients in group K suffered any side effects at 60 minutes. None of the patients from both groups developed pruritus. There were no significant differences in the development of nausea, vomiting, dizziness, and headache between the groups at each detection time. However, the overall number of patients who experienced nausea within 24 hours after surgery was significantly different between the groups $(\mathrm{P}=$ $0.002)$.

\section{DISCUSSION}

The present study findings showed gradual stabilization of vital signs after PCA application. The systolic and diastolic blood pressures and heart rate were consistently decreased within the normal ranges and there were no significant differences between the groups. The systolic and diastolic blood pressures gradually stabilized with appropriate pain control [21]. The heart rate decreased within 15 minutes since the PCA application and did not show any significant change afterwards [22]. The body temperature drops during the operation was recovered as well. None of the study subjects were administered with any additional antipyretics in the recovery room and the wards since none of them developed fever. The development of postoperative fever was prevented by ketorolac and propacetamol mixed in PCA [23-25].

The patients' subjective pain perception subsided in both groups after PCA applications. Varrassi et al. [26] reported a similar result by administrating $30 \mathrm{mg}$ of ketorolac and 2 g of propacetamol by IV drip infusion. Heo et al. [20] also reported a similar effect of $8 \mathrm{~g}$ of propacetamol mixed with fentanyl and ramosetron compared to $180 \mathrm{mg}$ of ketorolac through PCA. The present study provided similar results with $180 \mathrm{mg}$ of ketorolac and $10 \mathrm{~g}$ of propacetamol. Even though there was no statistical significance between the groups, the decrease in VAS was greater in the group P 15 minutes after PCA application. The rapid analgesic onset time of propacet- amol compared to delayed onset time of ketorolac $[12,14,15]$ may explain this finding. The amount of remifentanil used during the operation processes was not significantly different between the groups either (remifentanil amount used [median (IQR)]): group $\mathrm{K}=348 \mu \mathrm{g}$ (288-388), group $\mathrm{P}=354 \mu \mathrm{g}$ (290-398), $\mathrm{P}$ value $=0.659)$.

There were no significant differences between the groups in total fluid input volume and estimated blood loss. The median total fluid input volume of group K was $400 \mathrm{ml}$ (interquartile range [IQR]: 250-600) and that of group $\mathrm{P}$ was 350 ml (IQR: 25-450). The median estimated blood loss of group K was $40 \mathrm{ml}$ (IQR: 20-70) and that of group P was $30 \mathrm{ml}$ (IQR: 20-50). The laboratory workup results obtained 48 hours after PCA application revealed significant differences in $\mathrm{Hb}$, Hct, BUN, and INR between the groups but the differences were not clinically meaningful since the results were within the normal ranges. No evidence of hepatotoxicity or nephrotoxicity was found either.

There was no significant difference between the groups in development of vomiting, dizziness, and headache within 24 hours after surgery and none of the patients developed pruritus. These findings were also correlated to the findings of the previous study [20]. Although the development of nausea was not significantly different between the groups when analyzed at each detection time, the overall number of patients who experienced nausea was greater in group $\mathrm{P}$ than in group $\mathrm{K}$, with statistical significance. A possible explanation of this finding might be the effect of propacetamol as itself or the effect of $0.1 \mathrm{~g} / 5 \mathrm{ml} \times 10$ ampules of sodium citrate, a solution added to reduce injection pain of propacetamol. It is supported by a previous study result which reported that ingestion of sodium citrate induced nausea [27,28]. Although further studies are required to evaluate the effect of sodium citrate when administered intravenously with the use of propacetamol, it is suggested that the use of alternative solutions, such as normal saline, might prevent the development of the side effects. In addition, further studies with a large sample size are also required for the development of nausea. Until then, the application of propacetamol as indicated in the study should be cautiously performed for sensitive patients or patients who had experienced severe postoperative nausea and vomiting in the past.

The present study has several limitations. First, due to Berksonian bias, generalization of the present study find- 
ings is limited. Second, it would be more meaningful if the measurement time intervals were made more frequent and uniform. Third, the effect of PCA was more accurately examined if preoperative laboratory workup was compared with the results acquired right after the surgeries, 24 hours, and 48 hours after the PCA applications. Fourth, the degree of pain was obtained by evaluating resting, moving, and coughing pain (including during defecation) in average. Despite these limitations, the major strengths of this study include the following. The targeted patients were restricted to those with benign gynecologic diseases and only one selected surgeon was mainly involved in the operations so that the possible variabilities due to disease types and surgical processes were limited. In addition, objective physiologic effects were investigated by performing laboratory workup to compensate for subjective pain scores and development of side effects. Also, the developments of side effects were examined thoroughly for 24 hours after the surgery, by comparing the overall number of patients with side effects between the groups and the development of side effects at each measurement time between the groups.

Administration of PCA based on opioid combined with propacetamol showed no significant difference in pain control compared to PCA combined with ketorolac. Although the use of propacetamol was related to unexpected nausea in some incidences, it may be useful in patients with contraindications for ketorolac, including kidney problems, if additional attention is paid to the side effects. It could be an effective pain controller and an alternative of ketorolac in IV PCA after gynecologic surgeries.

\section{REFERENCES}

1. Hurley RW, Murphy JD, Wu CL. Acute postoperative pain. In: Miller's Anesthesia. 8th ed. Edited by Miller RD, Erikson LI, Fleisher L, Wiener-Kronish PW, Cohen NH, Young WL: Philadelphia, Churchill Livingstone/Elsevier. 2015, p 2979.

2. Butterworth JF, Mackey DC, Wasnick JD. Morgan and Mikhail's Clinical Anesthesia. 5th ed. New York, McGraw-Hill Education. 2013, p 190.

3. Marret E, Kurdi O, Zufferey P, Bonnet F. Effects of nonsteroidal antiinflammatory drugs on patient-controlled analgesia morphine side effects: meta-analysis of randomized controlled trials. Anesthesiology 2005; 102: 1249-60.
4. Cepeda MS, Carr DB, Miranda N, Diaz A, Silva C, Morales O. Comparison of morphine, ketorolac, and their combination for postoperative pain: results from a large, randomized, doubleblind trial. Anesthesiology 2005; 103: 1225-32.

5. Myles PS, Power I. Clinical update: postoperative analgesia. Lancet $2007 ; 369: 810-2$.

6. Macario A, Lipman AG. Ketorolac in the era of cyclo-oxygenase-2 selective nonsteroidal anti-inflammatory drugs: a systematic review of efficacy, side effects, and regulatory issues. Pain Med 2001; 2: 336-51.

7. Marret E, Flahault A, Samama CM, Bonnet F. Effects of postoperative, nonsteroidal, antiinflammatory drugs on bleeding risk after tonsillectomy: meta-analysis of randomized, controlled trials. Anesthesiology 2003; 98: 1497-502.

8. Gorissen KJ, Benning D, Berghmans T, Snoeijs MG, Sosef MN, Hulsewe KW, et al. Risk of anastomotic leakage with non-steroidal anti-inflammatory drugs in colorectal surgery. Br J Surg 2012; 99: 721-7.

9. Busti AJ, Hooper JS, Amaya CJ, Kazi S. Effects of perioperative antiinflammatory and immunomodulating therapy on surgical wound healing. Pharmacotherapy 2005; 25: 1566-91.

10. Lee A, Cooper MG, Craig JC, Knight JF, Keneally JP. The effects of nonsteroidal anti-inflammatory drugs (NSAIDs) on postoperative renal function: a meta-analysis. Anaesth Intensive Care 1999; 27: 574-80.

11. Catapano MS. The analgesic efficacy of ketorolac for acute pain. J Emerg Med 1996; 14: 67-75.

12. Delbos A, Boccard E. The morphine-sparing effect of propacetamol in orthopedic postoperative pain. J Pain Symptom Manage 1995; 10: 279-86.

13. Flouvat B, Leneveu A, Fitoussi S, Delhotal-Landes B, Gendron A. Bioequivalence study comparing a new paracetamol solution for injection and propacetamol after single intravenous infusion in healthy subjects. Int J Clin Pharmacol Ther 2004; 42: 50-7.

14. Campanero MA, Calahorra B, García-Quétglas E, López-Ocáriz A, Honorato J. Rapid liquid chromatographic assay for the determination of acetaminophen in plasma after propacetamol administration: application to pharmacokinetic studies. J Pharm Biomed Anal 1999; 20: 327-34.

15. Bannwarth B, Netter P, Lapicque F, Gillet P, Péré P, Boccard E, et al. Plasma and cerebrospinal fluid concentrations of paracetamol after a single intravenous dose of propacetamol. $\mathrm{Br}$ J Clin Pharmacol 1992; 34: 79-81.

16. Smith HS. Potential analgesic mechanisms of acetaminophen. Pain Physician 2009; 12: 269-80.

17. Burian M, Geisslinger G. COX-dependent mechanisms involved in the antinociceptive action of NSAIDs at central and peripheral 
sites. Pharmacol Ther 2005; 107: 139-54.

18. Woolf CJ, Chong MS. Preemptive analgesia--treating postoperative pain by preventing the establishment of central sensitization. Anesth Analg 1993; 77: 362-79.

19. Desmeules J, Rollason V, Piguet V, Dayer P. Clinical pharmacology and rationale of analgesic combinations. Eur J Anaesthesiol Suppl 2003; 28: 7-11.

20. Heo BH, Park JH, Choi JI, Kim WM, Lee HG, Cho SY, et al. A comparative efficacy of propacetamol and ketorolac in postoperative patient controlled analgesia. Korean J Pain 2015; 28: 203-9.

21. Pickering TG. Effects of stress and behavioral interventions in hypertension. Pain and blood pressure. J Clin Hypertens (Greenwich) 2003; 5: 359-61.

22. Terkelsen AJ, Mølgaard H, Hansen J, Andersen OK, Jensen TS. Acute pain increases heart rate: differential mechanisms during rest and mental stress. Auton Neurosci 2005; 121: 101-9.

23. Held BI, Michels A, Blanco J, Ascher-Walsh C. The effect of ketorolac on postoperative febrile episodes in patients after abdominal myomectomy. Am J Obstet Gynecol 2002; 187: 1450-5.
24. Kett DH, Breitmeyer JB, Ang R, Royal MA. A randomized study of the efficacy and safety of intravenous acetaminophen vs. intravenous placebo for the treatment of fever. Clin Pharmacol Ther 2011; 90: 32-9.

25. Warwick C. Paracetamol and fever management. J R Soc Promot Health 2008; 128: 320-3.

26. Varrassi G, Marinangeli F, Agrò F, Aloe L, De Cillis P, De Nicola A, et al. A double-blinded evaluation of propacetamol versus ketorolac in combination with patient-controlled analgesia morphine: analgesic efficacy and tolerability after gynecologic surgery. Anesth Analg 1999; 88: 611-6.

27. Oöpik V, Saaremets I, Medijainen L, Karelson K, Janson T, Timpmann S. Effects of sodium citrate ingestion before exercise on endurance performance in well trained college runners. Br J Sports Med 2003; 37: 485-9.

28. Kjaer K, Comerford M, Kondilis L, DiMaria L, Abramovitz S, Kiselev M, et al. Oral sodium citrate increases nausea amongst elective Cesarean delivery patients. Can J Anaesth 2006; 53: 77680. 